\title{
Epistemologi Kecerdasan Buatan (AI) dan Pentingnya IImu Etika dalam Pendidikan Interdisipliner
}

\author{
Michael Reskiantio Pabubung ${ }^{1}$ \\ ${ }^{1}$ Magister Filsafat Keilahian, Universitas Sanata Dharma Yogyakarta, Indonesia \\ E-mail: reskiantio.michael@gmail.com ${ }^{1}$
}

\begin{abstract}
Abstrak
Kecerdasan buatan (Al) adalah "payung istilah" yang digunakan untuk menyebut simulasi yang dilakukan oleh mesin-mesin atau alat, yang terhubung dengan samudera data, yang menyerupai kecerdasan manusia. Tidak diragukan lagi, Al sudah memberi dampak positif dalam banyak aspek kehidupan manusia yaitu ekonomi, pendidikan, pemerintahan, hingga pertahanan dan keamanan. Namun, Al bagaikan dua sisi mata uang yang juga memberikan dampak negatif. Adanya dampak multidimensi yang ditimbulkan oleh Al membawa pada suatu pertanyaan tentang cara mengimbangi kemajuan Al agar tetap terarah pada koridor yang diinginkan. Untuk menjawab persoalan ini, filsafat selalu mengawalinya dengan analisis epistemologis. Dengan berangkat dari fakta dan analisis epistemologis tentang $\mathrm{Al}$, penulis sampai pada keyakinan akan pentingnya peranan pendidikan interdisipliner. Dengan menggunakan metode kualitatif melalui analisis literatur tentang Al sebagai objek material, dan Filsafat khususnya epistemologi sebagai objek formal, tulisan ini menawarkan pentingnya Al dan ilmu Etika sebagai materi perkuliahan terpadu di tengah era dan disrupsi Al. Sebagai institusi pendidikan yang tanggap terhadap zaman, setiap universtas perlu mempertimbangkan perlunya materi perkuliahan tentang dasar-dasar Al dan Etika bagi setiap peserta didik.
\end{abstract}

Kata kunci: artificial intelligence; epistemologi; etika; interdisipliner.

\begin{abstract}
Artificial intelligence (Al) is an "umbrella term" used to describe simulations carried out by machines or devices, which are connected to an ocean of data, which resembles human intelligence. There is no doubt that Al has had a positive impact on many aspects of human life like an economy, education, government, defense, and security. However, Al is like two sides of a coin which also has negative impacts. The multidimensional impacts caused by Al leads to a question about how to keep pace with Al progress while staying through the desired path. To answer this question, philosophy always begins with an epistemological analysis. By departing from facts and epistemological analysis about Al, the author came to believe in the importance of the role of interdisciplinary education. By using qualitative methods through literature analysis on $\mathrm{Al}$ as a material object, and philosophy, especially epistemology as a formal object, this essay offers the importance of $\mathrm{Al}$ and Ethics as a compounded lecture material in the era and disruption of Al. As a time-responsive educational institution, every university needs to consider the necessity for lecture materials on the basics of $\mathrm{Al}$ and Ethics for every student.
\end{abstract}

Keywords: artificial intelligence; epistemology; ethics; interdisciplinary.

\section{Pendahuluan}

Saat ini kita sedang berada di tengah-tengah Revolusi Industri Keempat. Revolusi Industri Pertama yang terjadi pada abad kedelapanbelas dan berlanjut hingga abad kesembilanbelas terjadi dengan peralihan masyarakat agraris ke arah masyarakat industri dengan ditemukannya mesin uap. Revolusi Industri Kedua secara umum dikaitkan dengan tahun 1870-1914 yang dicirikan dengan penemuan baru bentuk-bentuk energi seperti listrik, minyak, dan baja yang menjadi dasar penemuan telefon, bohlam, dan mesin-mesin berbahan bakar. Revolusi Industri Ketiga mengacu kepada kemajuan teknologi modern, contohnya miniaturisasi yang menjadi dasar penggunaan komputer oleh setiap orang; Internet yang memberikan akses terhadap dunia pengetahuan secara luas dengan begitu mudahnya; dan kemajuan dalam dunia komunikasi seperti munculnya smartphone, Facebook, Instagram, Twitter, dan perangkat media sosial yang lain (Girasa, 2020).

Kemajuan teknologi khususnya tentang aplikasi pengetahuan praktis yang terjadi dalam beberapa dekade terakhir, telah mempertinggi kurva penciptaan micro-computer chips yang disandingkan dengan Internet akan segala hal (IOT) yang mengubah cara kita berpikir, bertindak, 
belajar, dan melakukan aktivitas dan kesibukan harian kita. Arus deras ini, yang lebih sering disebut sebagai "hot area", semakin meningkatkan investasi uang dan waktu yang mengakibatkan "disrupsi" dalam hidup sehari-hari. Salah satu disrupsi yang tak boleh diabaikan adalah disrupsi Artificial Intelligence (AI). Artificial intelligence (Al) adalah 'payung istilah' untuk menyebut simulasi proses kecerdasan dan pemikiran manusia oleh mesin-mesin yang terhubung dengan lautan data dan informasi. Mesin-mesin dibuat hampir menyerupai kapasitas dan kecerdasan manusia itu sendiri (Pabubung, 2021). Hingga kini, Al bisa terlihat secara nyata mulai dari aplikasi telepon pintar hingga mobil autokemudi; mulai dari mesin-mesin otomatis dan robot-robot di perusahaan-perusahaan hingga kamera-kamera pengawas (facial recognition) di sudut-sudut jalan. Kita juga mengenal adanya alat-alat canggih seperti Alexa, Siri, Cortana, dan Google Assistant, yang merupakan semacam asisten cerdas untuk mempermudah hidup masyarakat urban. Perkembangan Al sangat berpotensi untuk menciptakan perubahan masif dalam cara kita bertindak dan menjalani kehidupan sehari-hari (Pabubung, 2021). Disrupsi adalah sebuah fakta hidup yang terjadi terus-menerus manakala proses dan penemuan baru memasuki dunia pasar. Dalam disrupsi, kecemasan dan ketakutan menjadi hal yang pasti. Banyak pekerjaan yang akan hilang dengan sendirinya sebagai dampak dari suatu inovasi. Meski demikian akan lahir pula profesi-profesi baru, entah secara langsung atau tidak langsung, sebagai imbas dari teknologi-teknologi baru (Girasa, 2020). Perkembangan Al sesungguhnya menyisakan sebuah permasalahan mendasar yang lebih dari sekadar disrupsi. Sepertinya ada dimensi terdalam kemanusiaan yang terdampak oleh perubahan teknologi yang masif ini. Al tidak sekadar persoalan ekonomi, pendidikan, dan sosial politik. Ada hal mendasar dari sisi kemanusiaan yang tampaknya disasar oleh teknologi canggih ini (Pabubung, 2021).

Pada Desember 2016, Pontifical Academy of Sciences mengadakan workshop tentang Al dan ketika itu Stephen Hawking (1942-2018) memberikan sebuah komentar: "Keuntungan yang bisa diperoleh dari penciptaan Al yang baik sangatlah besar. Sebagai perangkat alat, Al dapat meningkatkan kecerdasan kita yang ada saat ini untuk menciptakan kemajuan di segala lini sains dan kemasyarakatan. Akan tetapi, ia juga bisa mendatangkan bahaya. Para pemerintah di seluruh dunia telah mulai menemukan perlombaan baru dalam senjata Al. Di masa depan, Al bisa berkehendak secara otonom, suatu kehendak yang akan sangat bertentangan dengan kehendak manusia... Singkatnya, Al bisa menjadi hal terbaik atau juga bisa menjadi hal terburuk yang pernah terjadi dengan kemanusiaan. Kita belum terlalu mengetahuinya. Itulah sebabnya, mengapa pada tahun 2014, saya dan beberapa rekan yang lain merasa terpanggil untuk mengadakan penelitian dengan fokus yang lebih pada bidang Al. Rasanya diskusi mengenai hal ini sangat penting untuk masa sekarang ini agar manfaatnya bisa dirasakan oleh manusia secara menyeluruh" (Hawking, 2017).

Saat ini kita sedang hidup dalam periode transisi drastis di mana jutaan pekerjaan sedang digantikan oleh perangkat terkomputerisasi, dengan akibat adanya disparitas tajam dalam hal penghasilan, dan terciptanya jurang-jurang pengetahuan (knowledge gaps). Memang ada banyak dampak dari teknologi baru ini. Tidak bisa disangkal bahwa sangat banyak dampak positif yang dihasilkan khususnya di masa Pandemi Covid-19. Kita bisa nyaman bekerja dan belajar dari rumah dengan adanya bantuan $\mathrm{Al}$ yang semakin canggih, kita bahkan bisa beramal dari rumah dengan adanya aplikasi-aplikasi berbasis Al untuk menjembatani hidup sosial kita. Tak terbayangkan bagaimana jadinya andaikan Pandemi Covid-19 melanda pada saat teknologi AI belum secanggih sekarang ini. Dengan adanya kecanggihan deep learning seperti yang tampak pada speech recognition kita dapat dapat memberi perintah kepada Google Assistant, Siri, Cortana dan Alexa untuk melakukan apa yang kita inginkan. Tentu, teknologi ini pasti akan semakin bekembang dan canggih di waktu-waktu mendatang. Google Assistant, Siri, Cortana, dan Alexa akan mampu mengolah kata-kata yang kita ucapkan untuk melakukan apa yang kita inginkan berdasarkan apa yang kita katakan. Ada lagi kecanggihan facial recognition misalnya pada kamera-kamera pengawas untuk mengidentifikasi setiap orang berdasarkan tangkapan gambar yang diperolehnya untuk mendapatkan identitas dan rekam jejak orang yang bersangkutan. Apakah teknologi jenis ini tidak bersifat tendensius, artinya tidak [digunakan untuk] menyasar orang-orang atau kelompok tertentu? Apakah identifikasi dan penampilan rekam jejak ini tidak melanggar privasi setiap manusia? Kecanggihan Al sangatlah luar biasa. la hampir saja menyamai kapasitas manusia khususnya untuk pekerjaan-pekerjaan yang sifatnya repetitif. Melalui machine learning dan deep learning, Al selalu belajar terus-menerus melalui trial-anderror hingga memenuhi atau bahkan melampaui Turing Test.

Dalam Taxonomy of Educational Objectives (1956) Benjamin S. Bloom membagi enam tingkatan pendidikan: [a] pengetahuan (knowledge) [b] pemahaman (comprehension) [c] aplikasi [d] analisis [e] sintesis [f] evaluasi. Tidak diragukan lagi kecanggihan Al telah sampai pada tiga 
tahap awal yakni, pengetahuan, pemahaman, dan aplikasi. Saat ini, dengan proses yang terus berlanjut dalam deep learning, Al sedang menyempurnakan kemampuan analisis (tahap keempat). Dalam proses analisis ini, ada lima tingkatan yang sedang dikembangkan dalam kecanggihan Al: analisis deskriptif, analisis diagnostik, analisis prediktif, analisis preskiptif, dan analisis kognitif. Al bahkan sedang dalam tahap advanced analysis (Soluciones, 2017). Jika melihat perkembangan Al saat ini dari sudut pandang Bloom, maka yang tersisa untuk manusia hanyalah tingkatan kelima (sintesis) dan keenam (evaluasi). Maka pendidikan harus sampai pada tahap sitesis dan evaluasi. Produk ideal pendidikan di era Al tidak bisa sebatas kemampuan untuk memiliki informasi, mengetahui, memahami, mengaplikasikan, dan menganalis. Produk ideal pendidikan harus sampai pada sintesis dan evaluasi (Soozandehfar, 2016).

Fenomena ini memberikan tantangan bagi dunia pendidikan. Pendidikan seperti apa yang bisa mencapai sintesis dan evaluasi? Sebelum menjawab pertanyaan ini kita perlu menganalisis seperti apa epistemologi Al. Oleh karena itu, tulisan ini hendak menjawab dua pertanyaan mendasar: Apa sebenarnya epistemologi Al? Bagaimana institusi pendidikan mempersiapkan para peserta didik menghadapi era AI? Fenomena Al adalah tantangan bersama. Di satu sisi AI membawa manfaat yang sangat baik di banyak lini kehidupan. Di sisi lain, ada masalah-masalah yang harus dihadapi berkaitan dengan keikutsertaan dalam era Al. Tulisan ini memberikan sebuah solusi praktis dalam bidang pendidikan melalui pendidikan interdisipliner (Graff, 2016) dengan penekanan pada IImu Etika.

\section{Metode}

Tulisan ini menggunakan metode kualitatif melalui analisis literatur. Data yang digunakan dalam tulisan ini berasal dari jurnal, buku, dan artikel yang terkait dengan epistemologi, etika, artificial intelligence, dan pendidikan interdisipliner dengan fokus pada terbitan sepuluh tahun terakhir. Kajian ini menggunakan artificial intelligence sebagai objek material dan epistemologi sebagai objek formal.

\section{Hasil dan Pembahasan}

John L. Pollock (1940-2009), seorang filsuf dari Amerika bidang Epistemologi dan Al, mengatakan bahwa epistemologi terkait dengan ragam pertanyaan, namun satu pertanyaan pokok terkait epistemologi adalah apa yang bisa disebut sebagai "pemeliharaan keyakinan rasional (rational belief maintenance)". Ini menyangkut bagaimana mempertahankan dan membarui (update) sistem keyakinan-keyakinan kita sebagai tanggapan terhadap input-input indra yang baru dan terhadap 'pertanggungjawaban' lanjutan (further reasoning) atas keyakinankeyakinan terdahulu yang kita anut (Pollock, 1990). Pollock menggunakan istilah 'pertanggungjawaban' (reasoning) dalam pengertian yang luas. Menurutnya, pertanggungjawaban teoretis perlu manakala kita mau mengadopsi teori yang baru dan 'memperbaiki' keyakinan-keyakinan lama. Hal ini melahirkan sebuah istilah teknis "pembenaran epistemik" (epistemic justification). Pembenaran epistemik mengandung keyakinan-keyakinan yang dianut dalam kaitan dengan aturan pemeliharaan keyakinan (belief maintenance) yang terkandung dalam arsitektur rasional kita. Epistemologi adalah menyangkut kompetensi mempertanggungjawabkan secara rasional (reasoning competence) (Pollock, 1990; Fumerton, 2017).

Para filsuf telah mengimpikan Al selama berabad-abad. Hobbes dan Leibniz, dalam cara yang sangat berbeda, mencoba untuk mengeksplorasi implikasi dari ide dengan mengurai pikiran ke dalam bentuk operasi yang sangat kecil, yakni yang bersifat mekanis. Menurut Daniel C. Dennett (1942-...), seorang filsuf dan ilmuwan kognitif dari Amerika Serikat, Descartes bahkan telah mengantisipasi Turing Test dan tidak ragu untuk mengeluarkan sebuah prediksi yang meyakinkan dengan hasil yang memang sungguh terjadi (Dennett, 1988). Descartes mengatakan, "Sesungguhnya sangat mungkin bahwa sebuah mesin dapat dibuat untuk mengucapkan kata-kata, dan bahkan kata-kata yang memungkinkan hadirnya tindakan fisik; misalnya, jika mesin itu disentuh pada satu titik tertentu, maka ia akan menanyakan keinginanmu, atau dia pun bisa menangis ketika disakiti, dan beragam hal yang serupa. Namun mesin ini tidak akan pernah mampu mengubah frasa yang sudah tertanam dalam dirinya untuk menanggapi segala macam pertanyaan atau perintah secara tiba-tiba, suatu hal yang bahkan bisa dilakukan oleh orang yang paling bodoh" (Descartes, 1637). Dengan perkataan lain, secerdas apapun, Al tidak punya 'kemandirian' berpikir sebagaimana yang dimiliki oleh manusia. Al dapat memberi 
jawaban dan keputusan berdasarkan rumus-rumus yang tertanam dalam sistem, sedangkan manusia tidak pernah terikat pada rumus-rumus manapun (Gut, 2020).

Hal yang paling khas dalam diri manusia yang berakal budi adalah kemampuan untuk memberikan pertimbangan-pertimbangan moral. Dalam segala hal manusia adalah agen moral. Kecerdasan Al yang luar biasa tak ada kaitannya dengan pertanggungjawaban moral, karena moralitas selalu menyangkut manusia yang tahu, mau, dan sadar. Persis dalam ranah moral ini jugalah, manusia perlu mengevaluasi kinerja Al. Masalah umum yang selalu muncul adalah mengenai penggunaan sistem Al secara bertanggung-jawab, serta adanya pertimbangan moral dalam setiap pengembangan Al. Bagaimana para pengembang bisa memastikan bahwa teknologi Al yang dikembangkan, khususnya machine learning dapat mengambil keputusan dengan tepat dan dapat dipertanggung-jawabkan? Salah satu jawaban yang bisa diperoleh adalah adanya pelatihan sistem dalam hal akurasi statistik, dan kemudian penambahan perangkat lapisan ekstra (extra layer processing) untuk memperoleh keyakinan bahwa keputusan yang diambilnya semakin mampu diaplikasikan secara bertanggung-jawab. Pendekatan yang kedua adalah melatih tanggung-jawab ke dalam sistem yang diciptakan sejak awal, dengan memastikan bahwa serangkaian latihan yang dilakukan tidak mengabaikan pola-pola responsibilitas (does not encode some pattern of irresponsibility). Namun dengan segala hormat, kita dapat mengatakan bahwa teknik ini sekadar merupakan "pertanggungjawaban syarat" (modular responsibility) dan bukan "pertanggungjawaban dasariah" (ingrained responsibility). Godaan untuk lebih condong ke arah pertanggungjawaban modular sangat kuat sehingga mengalahkan pertanggungjawaban dasariah yang mestinya wajib diupayakan (King, 2019).

Saat ini, ada sebuah perlombaan untuk menjadi superpower teknologi Al melalui terobosan-terobosan untuk menjadi pengembang Al terbaik. Banyak negara seperti Amerika Serikat, Singapura, Jepang, Kanada, dan Cina menggelontorkan banyak uang untuk pembangunan dan pengembangan penelitian Al. Di balik hiruk-pikuk pengembangan Al, ada koridor dan standar yang harus dipenuhi untuk memastikan bahwa penelitian, pengembangan, dan penggunaan Al memenuhi kaidah etis. Meski demikian, tetap ada banyak perdebatan di seputar etika Al. Meski demikian harus ditanamkan dalam ingatan bahwa buaian yang mengatakan bahwa Al sangat berpengaruh positif bagi kehidupan dan masyarakat adalah sebuah idealisme. Oleh karena itu, perlu adanya penelitian dan pengembangan kritis untuk menciptakan Al yang aman dan berlandaskan etika. Saat ini, ada banyak ancaman yang akan ditimbulkan oleh Al: pengangguran, kemanusiaan, kesenjangan, bias dalam algoritma, supremasi algoritma, fake news and fake videos, transparansi algoritma, perlombaan senjata, privasi dan pengawasan (surveillance), automasi, dan error prevention (Ramar,2019).

Bagi Dennett (1988) kebanyakan dari proyek AI merupakan ekstrapolasi dari hal-hal yang dapat dilakukan, dan itu semua lebih pada eksperimen pemikiran (thoughts experiment) dibandingkan eksperimen empiris (empirical experiment). Contoh konketnya adalah ketika sudah berbicara tentang NLP dan deep learning. Eksperimen pemikiran dalam Al menurut Dennett berbeda dari eksperimen pemikiran filosofis. Namun perbedaannya bukan pertama-tama dari isinya, melainkan dari metodologinya. Eksperimen pemikiran Al mengganti beberapa latarbelakang asumsi intuitif dan hal-hal yang masuk akal (plausible) dalam eksperimen filosofis dengan diktasi terbatas karena tuntutan model yang harus dibuat untuk menjalankan komputer. Batasan-batasan waktu dan ruang ini serta pentingnya spesifikasi (exigencies of specification) dapat disilangkan satu sama lain dalam cara yang tidak terbatas secara praktis agar "mesinmesin virtual baru" dapat dihadirkan dalam arsitektur serial komputer digital. Sangat kecil kemungkinan bahwa seorang filsuf akan terkesan dengan eksperimen pemikirannya sendiri, namun dalam Al hal itu sangat besar kemungkinannya. Itu sudah terbukti sepanjang waktu perjalanan Al. Layaknya para filsuf, para peneliti Al menyambut setiap tawaran atau usulan baru dengan penilaian intuitif (intuitive judgement) tentang prospek-prospeknya, disokong oleh argumen-argumen apriori mengenai mengapa sebuah fitur tertentu harus ada; atau tidak boleh diciptakan. Namun, tidak sama dengan para filsuf, para peneliti Al tidak mempertahankan argumen dan intuisinya mati-matian; sebaliknya mereka menyediakan ruang bagi dirinya untuk merasakan keterpukauan atas hasil dan penemuan-penemuan baru, sebuah kejutan yang hanya bisa dirasakan lantaran adanya sebuah tampilan, suatu daya yang tak dibayangkan sebelumnya dari suatu sistem temuan baru (Dennett, 1988).

Jika demikian, apakah AI menjadi bagian dari ilmu alam (natural science) atau ilmu sosialkebudayaan? Bagi Ganascia (2010), Al bisa menjadi bagian dari keduanya. Ilmu sosial mencoba untuk memahami tindakan-tindakan manusia, seperti tujuan manusia dan cara manusia mencapai tujuan-tujuan itu. Lantaran AI mencoba untuk mereproduksi tindakan cerdas manusia, maka ia bisa menggunakan metode 'ilmu sosial'. Namun Al juga bisa menggunakan metode 'ilmu 
alam' misalnya dari matematika dan logika menyelidiki mekanisme fisiologis. Bagi Ganascia, seorang professor bidang computer science dari Sorbonne University, Al memang tampak sebagai bagian dari 'ilmu alam' [karena lahir dari generalisasi kasus-kasus melalui metode induktif], namun sekaligus juga bagian dari 'ilmu sosial' [karena mengkarakterisasi hal-hal artifisial berdasarkan fungsi, tujuan, dan adaptivitasnya, dan bukan hanya berdasarkan strukturnya melalui metode deduktif] (Ganascia, 2010).

'Artifisialitas' diambil dari istilah Herbert Simon (1996). Menurut Simon, artifisialitas bukan hanya menyangkut hal-hal yang dihasilkan oleh aktivitas adaan-adaan cerdas (intelligent beings), tetapi juga tujuan-tujuan untuk apa mereka didesain. Ciptaan manusia tidak dapat direduksi pada hal-hal material yang dihasilkan (Fumerton, 2017). Sebagai contoh, sebuah patung lebih pada sekadar perunggu yang dikandungnya; sebuah jam lebih dari sekadar logam yang menyusunnya; sebuah buku lebih dari sekadar kertas dan tinta yang mengisinya. Sebagai sebuah konsekuensi, artifisialitas juga menjadi bagian dari kulturalitas (sosial). IImu yang menghasilkan artifak, yakni 'ilmu artifisial' tak diragukan lagi menjadi bagian dari 'ilmu sosial-kebudayaan'. Kebudayaan mencakup wilayah yang luas karena juga menyertakan aktivitas interpretasi murni seperti sejarah. Lagipula, logika 'ilmu sosial-kebudayaan' merupakan perluasan logika yang digunakan dalam 'ilmu-ilmu artifisial' yang tetap memiliki kesamaan dengan 'ilmu-ilmu alam' (Ganascia, 2010).

Dari sudut pandang filosofis, dapat dikatakan bahwa Al berpartisipasi dalam 'ilmu kebudayaan' [karena tidak dapat secara penuh direduksi ke dalam 'ilmu alam', atau matematika dan ilmu-ilmu teoretis]. Namun ia juga tidak dapat direduksi pada 'ilmu sosial-kebudayaan'. Persisnya, ia masuk ke dalam area yang disebut oleh Heinrich Rickert (1921) sebagai "intermediary domain". Intermediary domain secara simultan menjadi bagian dari ilmu-ilmu teoretis yakni logika formal dan matematika, ilmu-ilmu alam empiris (empirical sciences of nature) dan ilmu-ilmu kebudayaan empiris (empirical sciences of culture). Konsekuensi praktis dari pertimbangan filosofis seperti ini ada dua: memiliki dampak baik bagi metode maupun objek aplikasi Al.

Dari sisi metode, lantaran Al menjadi bagian dari "ilmu sosial-kebudayaan", ia harus menggunakan logika "ilmu sosial-kebudayaan" yang dapat memperluas cakupan metodenya. IImu sosial-kebudayaan adalah ilmu empiris yang membangun pengetahuan dari observasi halhal partikular. Namun demikian, ilmu ini tidak mengabstraksi pengetahuan dari hal-hal partikular. Data dikumpulkan dari kasus-kasus individual, dipahami, lalu menemukan penyebab umum. Dapat dikatakan bahwa ilmu ini tidak bermaksud mengekstraksi singularitas, tetapi menyelidiki kasus-kasus paradigmatis dan menjelaskan penyebab kasus individual tersebut di bawah studi yang berlaku secara umum (Ganascia, 2010).

Dari sisi objek kajian, Al dapat berfokus pada dimensi kebudayaan dunia di mana terdapat ragam aplikasi bermakna. Ilmu-ilmu teknologi dan informasi berkontribusi besar bagi kemajuan pengetahuan khususnya karena zaman sekarang ini disebut-sebut sebagai "knowledge age", dan juga bagi kemanusiaan di saat Al sering terdengar sebagai 'ancaman' bagi manusia. Namun, demikian dalam kenyataan, menjadi hal yang patut disayangkan karena Al belum berpartisipasi secara aktif dalam evolusi kebudayaan, sebagai konsekuensi dari pengembangan teknologi informasi (Ganascia, 2010).

Al tidak dapat direduksi baik kepada "IImu Alam" [metode induktif] maupun kepada "IImu Sosial-Kebudayaan" [metode deduktif]; inilah yang disebut oleh Ricket sebagai intermediary domain. Hal ini tidak hanya memiliki implikasi filosofis terhadap status epistemologis Al, tetapi juga memiliki konsekuensi praktis baik dalam hal objek ataupun metode Al. Oleh karena itu kajian ilmu humaniora terhadap Al bukanlah kajian 'tambahan' atau pelengkap tetapi merupakan kajian esensial bagi pengembangan Al.

Hal ini sejalan dengan yang disuarakan oleh Klaus Mainzer dalam bagian akhir karyanya, Artificial Intelligence. When Do Machines Take Over? (2020), sebagai sesuatu yang sangat penting. la mengatakan "Pertanyaan-pertanyaan mengenai kemanusiaan dan ilmu-ilmu sosial harus dimunculkan sejak awal dalam sebuah desain teknologi dan bukan sekadar 'tambahan' yang datang belakangan setelah teknologi yang baru sudah tercipta" (Mainzer, 2020). Masalahnya, selama ini pertimbangan-pertimbangan etis baru selalu datang belakangan sehingga tidak banyak membuat perubahan, bahkan kadangkala sekadar wacana. Bagi Mainzer, hubungan antara sains, teknologi, dan masyarakat harus dikaji dari tiga perspektif. (1) Studi Sains dan Teknologi: para ilmuwan sosial dan pakar humaniora perlu meneliti aspek-aspek sosial dari sains dan teknologi. (2) Etika dan Responsibilitas: para ahli etika dan moral perlu mengkaji dari sisi medis [moral hidup] dan ekonomi [moral sosial] untuk mengevaluasi penelitian dan pengembangan kecerdasan buatan. (3) Ilmu Komunikasi dan Media: para ahli ilmu komunikasi 
menguji bagaimana artificial intelligence dapat memajukan proses pertukaran ide dan informasi (Mainzer, 2020).

Mainzer menegaskan, "Kajian dalam ilmu humaniora tentang Al perlu membantu para insinyur generasi mendatang, ahli komputer, dan para ilmuwan [alam] untuk membaktikan karyakarya mereka bagi kemaslahatan masyarakat [manusia]. Oleh karena itu, sangat penting bahwa setiap (maha)siswa atau pelajar dari semua bidang perlu peka akan hal ini. Pertanyaan besar mengenai masa depan artificial intelligence hanya dapat terjawab melalu kerja-sama interdisiplinaritas" (Mainzer, 2020; Graff, 2016). Dalam konteks pembicaraan kita ini, ahli Al harus terbuka terhadap kritik dan saran dari bidang lain khususnya dalam Etika. Dalam dunia akademis, Etika menjadi koridor yang tepat untuk dilalui jika menginginkan terciptanya hasil temuan yang bermanfaat bagi manusia dengan tetap menjunjung kemanusiaan. Kerja sama antara ahli Al dan Etika menjadi contoh yang sangat baik bagi terciptanya program pendidikan interdisipliner yang efektif dan efisien (Graff, 2016).

Saat ini, orang-orang di berbagai penjuru dunia termasuk di Indonesia berbicara tentang STEM. STEM adalah singkatan dari science, technology, engineering, mathematics. Keempat pilar ini menjadi empat pilar utama dalam teknologi artificial intelligence. Pembicaraan tentang STEM dirasa sangat penting mengingat dunia dan Indonesia sangat membutuhkan lulusanlulusan yang berkompeten dalam bidang-bidang ini. Dunia sedang menghadapi era industrialisasi yang berbasis pada teknologi kecerdasan buatan. Inilah yang digaungkan oleh Klaus Schwab (2016) dalam bukunya The Fourth Industrial Revolution. Dalam slogan "Making Indonesia 4.0", pemerintah Indonesia juga menggalakkan sebuah visi teknologi dunia dalam bidang STEAM yang menekankan pentingnya keahlian-keahlian ini dalam bidang industri manufaktur. Oleh karena itu, pemerintah akan memberi fokus pada kurikulum yang memberi penekanan pada STEAM ini (Kementerian Perindustrian RI, 2016). Tidak ada salahnya jika pemerintah hendak berfokus pada pengembangan bidang ini, asalkan bidang-bidang lain juga tetap mendapat prioritas khususnya bidang etika.

Ada sebuah fakta yang menarik. Di tengah persaingan ketat negara-negara dan perusahaan-perusahaan dalam bidang Al, perhatian terhadap Al dalam hubungannya dengan etika kian meningkat pula (Jobin, 2019). Ada banyak pihak yang ikut terlibat dalam diskusi dan perdebatan mengenai Al: mulai dari OECD (2019) hingga Uni Eropa (European Group on Ethics in Sciences and New Technologies, 2018) dan UNESCO (2019); dari perusahaan privat seperti Microsoft (Shaw, 2019), IBM (Cutle, 2019), Google (2019) hingga asosiasi perindustrian yang lain (Association for Computing Machinery US Public Policy Council, 2017). Salah satu kontribusi yang menarik berasal dari The Institute of Electrical and Electronics Engineers Global Initiative on Ethics of Autonomous and Intelligent Systems yang secara komprehensif memetakan masalah dan tantangan yang sedang muncul atau akan ada di masa depan (IEEE, 2019). Fakta ini menunjukkan bahwa STEM memang penting, tetapi bidang etika tidak kalah penting. Etika bagaikan spidometer pada kendaraan atau wasit dalam pertandingan sepakbola. Kita tentu tidak ingin mengemudikan kendaraan yang tidak dilengkapi dengan spidometer karena bisa mengakibatkan kecelakaan fatal akibat kecepatan yang tidak terukur. Kita juga pasti tidak mau menyaksikan pertandingan sepak bola tanpa wasit karena akan menciptakan permainan yang tidak fair dan rawan konflik. Seorang wasit tidak perlu menguasai teknik menggiring bola atau teknik menendang ke gawang, namun ia wajib menilai tindakan-tindakan yang benar dan salah dalam permainan agar mampu mengambil keputusan. Hal yang sama terjadi dengan kapasitas seorang ahli etika. la tidak harus menguasai hal teknis misalnya dalam hal coding dan pemrograman, namun wajib menguasai hal mendasar mengenai boleh-tidaknya program ini diciptakan dan diterapkan pada manusia.

Prinsip permainan yang fair dalam pertandingan sepakbola tidak hanya wajib dikuasai oleh wasit, tetapi juga oleh semua pihak baik oleh pemain sendiri, para pelatih dan manajer, dan juga para penonton. Semua pihak yang terlibat harus menciptakan suasana yang fair dan sportif. Walau wasitnya fair dan berkompeten tetapi jika pemain bersikap curang dan menganggap kecurangan dan pelanggaran sebagai hal yang benar, maka akan terjadi konflik. Kita sebagai penonton di rumah pasti kecewa menyaksikan pertandingan yang tidak fair dan sportif. Walau wasit, manajer, dan pemain sudah bermain dengan sportif dan fair tetapi jika penonton tidak mau menerima kekalahan, maka konflik akan terjadi. Tidak jarang ada yang menjadi korban jiwa dari tawuran antarpendukung kesebelasan. Hal yang sama terjadi dengan problem etis yang sedang dibahas berkaitan dengan Al.

Para ahli etika dan komisi etik di bidang pemerintahan dan bisnis dapat diibratkan sebagai wasit. Pemerintah, pemilik perusahaan, dan pejabat negara dapat diibaratkan sebagai pelatih dan manajer. Aparatur sipil negara, ahli teknologi, periset, dan karyawan dapat diibaratkan 
sebagai para pemain. Sementara itu, masyarakat luas sebagai konsumen dapat diibaratkan sebagai penonton sepak bola. Supaya permainan dapat fair dan sportif secara utuh, perlu ditanamkan semangat fairness dan sportivitas dalam diri setiap orang. Bagaimana caranya? Jawabannya adalah melalui pendidikan. IImu Etika dan Al dalam pendidikan interdisipliner adalah pengetahuan tentang fairness dan sportivitas dalam mencapai kebahagiaan hidup bersama atas dasar pemeliharaan kemanusiaan sebagai bekal untuk kemampuan sintesis dan evaluasi.

\section{Simpulan dan Saran}

Untuk memfasilitasi tujuan baik ini dibutuhkan dua hal (a) kurikulum tentang pengetahuan dasar Al dan dignitas manusia di sekolah menengah kejuruan (SMK); (b) mata kuliah dasar tentang dasar-dasar Al dan Etika di setiap program studi pada perguruan tinggi baik swasta maupun negeri. Mengapa SMK? Lulusan SMK adalah mereka yang sudah siap untuk terjun di dunia kerja. Kebanyakan dari mereka terjun ke dalam dunia industri teknologi yang berkaitan langsung dengan Al di masa depan. Oleh karena itu, pendidikan etika dasar adalah hal yang wajib untuk SMK. Tujuannya adalah untuk menghasilkan 'calon-calon pemain' yang sportif dan fair. Mengapa Al dan Etika perlu menjadi mata kuliah dasar di setiap program studi? Ini sangat erat kaitannya sebagai 'para pemain' dan 'para penonton'. Sebagai calon pemain khususnya mereka yang mengambil bidang teknologi informatika, computer science, dan manajemen bisnis, mereka perlu dibekali dasar-dasar etika, misalnya melihat apakah produk ciptaan atau gagasan mereka tentang teknologi canggih berbasis Al tidak diskriminatif dan tidak melanggar privasi setiap individu. Di era Al, kita semua akan menjadi konsumen Al [bahkan juga produsen] dalam arti tertentu. Dalam analogi pertandingan sepak bola kita ibarat para penonton. Kita semua perlu dibekali pemahaman mendasar mengenai dasar-dasar Al dan dignitas manusia demi membentuk diri sebagai 'konsumen kompeten' atau 'penonton yang sportif'. Ada sebuah fakta menarik. Berdasarkan survei pribadi melalui google form pada tanggal 15-22 April 2021 kepada mahasiswa Universitas Sanata Dharma dan Universitas Atma Jaya-Yogyakarta, sebanyak 93.3\% dari 60 responden menyetujui perlunya mata kuliah dasar-dasar Al dan Dignitas Manusia (Etika) di setiap program studi. Antusiasme para peserta didik seperti ini bisa menjadi salah satu indikator bagi universitas untuk mempertimbangkan perlunya pendidikan interdisipliner khususnya soal $\mathrm{Al}$ dan Etika di era Al yang sedang dan akan kita hadapi. Kolaborasi Al dan Etika diharapkan menjadi pintu untuk memasuki ranah kemampuan sintesis dan evaluasi bagi setiap peserta didik.

\section{Daftar Pustaka}

Association for Computing Machinery US Public Policy Council. 2017. Statement on Algorithmic Transparency and Accountability. Dalam USACM \& ACM 2017. Diakses dari https://www.acm.org/binaries/content/assets/public-

policy/2017_joint_statement_algorithms.pdf (diakses 02.02.2021).

Bloom, Benjamin S. 1956. Taxonomy of Educational Objectives. Michigan: Longmans.

Cutle A. et al. 2019. Everyday Ethics for Artificial Intelligence. New York: IBM.

Dennett, Danel C. 1988. When Philosophers Encounter Artificial Intelligence. Daedalus. The MIT Press on behalf of American Academy of Arts \& Sciences, Vol. 117, No. 1: pp. 283-295. Girasa, Rosario. 2020. Artificial Intelligence as a Disruptive Technology. Cham: Palgrave Macmillan.

Descartes, Rene. 1637. Discourse on Method. Diterjemahkan oleh Laurence J. LaFleur. 1960. New York: Bobbs-Merrill.

European Group on Ethics in Science and New Technologies. 2018. Statement on Artificial Intelligence, Robotics and "Autonomous" Systems. Brussels: European Commission. Diakses dari https://www.unapcict.org/sites/default/files/2019-01/EC_Al-\%20Robotics\%20and\%20Autonomous\%20Systems.pdf (diakses 28.01.2021).

Fumerton, Richard. 2017. Epistemology and Science: Some Metaphilosophical Reflections. Philosophical Topics. Vol. 45, No. 1: pp. 1-16.

Ganascia, Jean-Gabriel. 2010. Epistemology of Al Revisited in the Light of the Philosophy of Information. Knowledge and Policy. June 2010, 11. Diakses dari https://www.researchgate.net/publication/226009851.

Google. 2019. Perspectives on Issues in Al Governance. Mountain View: Google. 
Graff, Harvey J. 2016. The "Problem" of Interdisciplinarity in Theory, Practice, and History. Social Sience History. Vol. 40, No.4 : pp. 775-803.

Gut, Przemyslaw dan Arkadiusz Gut. 2020. The Highlight of Descartes' Epistemology. Annals of Philosophy. Vol. 68, No. 2: pp. 9-20.

Hawking, Stephen. 2017. Comments: The Ethics of Artificial Intelligence. Dalam Antonio M. Battro dan Stanislas Dehaene (eds). Power and Limits of Artificial Intelligence. Vatican: Pontificia Academia Scientiarum, Libreria Editrice Vaticana.

IEEE. 2019. Ethically Aligned Design. New York: IEEE.

Jobin, A. et al. 2019. Artificial Intelligence: the global landscape of ethics guidelines. Nature Machine Intelligence. Vol.1: pp.389-399.

Kementerian Perindustrian RI. Making Indonesia 4.0. Kementerian Perindustrian RI, 2016, Diakses dari https://kemenperin.go.id (diakses 16.04.2021).

King, Owen C. 2019. Machine Learning and Irresponsible Inference: Morally Assessing the Training Data for Image Recognition Systems. Dalam Don Berkich dan Matteo Vincenzo (eds). On the Cognitive, Ethical, and Scientific Dimensions of Artificial Intelligence. Cham: Springer.

Mainzer, Klaus. 2020. Artificial Intelligence. When do Machines Take Over? Cham: Springer.

OECD. 2019. Recommendation of the Council on Artificial Intelligence. OECD Legal Instruments. Diakses dari https://legalinstruments. oecd.org/en/instruments/OECD-LEGAL-0449 (access 11.12.2020).

Pabubung, Michael Reskiantio. 2021. Human Dignity Menurut Yohanes Paulus II dan Relevansi terhadap Kecerdasan Buatan (Al). Jurnal Teologi. Vol. 10, No. 1: pp. 49-70.

Pollock, John. 1990. Philosophy and Artificial Intelligence. Philosophical Perspectives, 1990, Vol. 4, Action Theory and Philosophy of Mind: pp. 461-498.

Ramar, Sachin. 2019. Artificial Intelligence. How It Changes the Future. t.k: t.p.

Rickert, H. 1921. Kulturwissenschaft und Naturwissenschaft. J.C.B. Tubingen: Max Niemeyer.

Rieder, Bernhard. 2020. Engines of Order: A Mechanology of Algorithmic Techniques. Amsterdam: Amsterdam University Press.

Schwab, Klaus. 2016. The Fourth Industrial Revolution. Geneva: World Economic Forum, 2016.

Shaw, G. 2019. The future computed: Al \& Manufacturing. Seattle: Microsoft.

Simon, H.A. 1996. The Sciences of the Artificial. Massachusetts: MIT Press.

Soluciones, Decide. 2017. Let's Talk About Advanced Analytics: A Brief Look at Artificial Intelligence. Medium. Diakses dari https://becominghuman.ai/lets-talk-about-advancedanalytics-a-brief-look-at-artificial-intelligence-bf1c7a7d3f96 (diakses 21.04.2021).

Soozandehfar, S.M.A. dan M.R. Adeli. 2016. A Critical Appraisal of Bloom's Taxonomy. American Research Journal of English and Literature. Vol 2.

UNESCO. 2019. Beijing Consensus on Artificial Intelligence and Education. UNESDOC Digital Library, 2019. Diakses dari https:// unesdoc.unesco.org/ark:/48223/pf0000368303 (diakses 28.01.2021). 